\title{
Fabrikasi Kapal Fiberglass Sebagai Bahan Alternatif Pengganti Kapal Kayu Untuk Meningkatkan Produktifitas Nelayan Di Perairan Bengkalis
}

\author{
Pardi $^{\left.l)^{*}\right)}$, Afriantoni ${ }^{l)}$ \\ 1)Jurusan Teknik Perkapalan, Politeknik Negeri Bengkalis , Indonesia \\ Jl. Bathin Alam, Bengkalis,Indonesia
}

\begin{abstract}
Abstrak
Ketersediaan material kayu sebagai bahan baku kapal nelayan saat ini semakin menipis. Hal ini menjadi masalah yang serius bagi sebagian besar masyarakat kabupaten Bengkalis yang berprofesi sebagai nelayan. Oleh karena itu dalam penelitian ini memberikan solusi secara ilmiah untuk menggunakan bahan alternatif fiberglass sebagai bahan dasar fabrikasi kapal nelayan. Penelitian ini membahas tentang cara fabrikasi kapal fiberglass yang efektif dengan ukuran utama sebagai berikut : $L p p=7,798 m, B=1,575 m, H=0,678 m, T=0,4 m$ dan $C b=0,449$. Gambar desain yang digunakan untuk fabrikasi adalah gambar rencana garis (lines plan) dan gambar rencana umum (general arrangement). Langkah awal proses fabrikasi adalah membuat cetakan positif menggunakan material kayu dan multiplek. Cetakan positif lambung kapal mengikuti bentuk body kapal disesuaikan dengan gambar rencana garis setiap station. Sebelum proses laminasi dilakukan menggunakan material resin, serat glass (matt), woven roving(WR), katalis dan tepung aerosil cetakan diberi mirorglass untuk mempermudah pelepasan hasil cetakan. Ketebalan yang digunakan pada pembuatan lambung kapal ini adalah sekitar 6 mm atau 6 layer. Setelah lambung selesai dilaminasi kemudian dibuat gading (frame) memanjang dan melintang sesuai dengan desain gambar general arrangement. Sekat dan bangunan atas dibuat bentuknya menggunakan multiplek $12 \mathrm{~mm}$ kemudian dilaminasi menggunakan fiberglass untuk memperkuat dan menghindari kerusakan karena faktor air laut.
\end{abstract}

Copyright (C) 2017, KAPAL, ISSN:1829-8370

Kata Kunci : Fiberglass, fabrikasi kapal, nelayan, body kapal, laminasi, cetakan

\section{PENDAHULAN}

Kapal kayu merupakan fasilitas yang dipergunakan masyarakat yang tinggal didaerah pesisir Bengkalis dengan berprofesi sebagai nelayan penangkap ikan. Karena keterbatasan ekonomi yang mereka hadapi sebagian dari nelayan tersebut menggunakan kapal dan alat tangkap yang sangat sederhana. Dengan semakin berkurangnya ketersediaan hutan penghasil kayu menjadi masalah yang sangat serius bagi nelayan terutama untuk kebutuhan kapal baru maupun untuk perbaikan kapal kayu mereka.

Oleh karena itu dalam penelitian ini membahas tentang fabrikasi kapal dengan menggunakan bahan alternatif berupa fiberglass.

*) Penulis Korespondensi :

Email : pardi@polbeng.ac.id
Berdasarkan hasil penelitian sebelumnya diketahui bahwa biaya produksi yang dikeluarkan kapal kayu lebih mahal jika dibandingkan dengan kapal fiberglass. Biaya penyusutan dan perawatan yang dikeluarkan kapal kayu juga lebih besar jika dibandingkan dengan kapal fiberglass (Anwar Khaerul, 2012). Namun penelitian sebelumnya masih belum menjelaskan tahapan fabrikasi secara detail, sedangkan dalam penelitian ini proses fabrikasi yang dilakukan mempertimbangkan efektivitas dan kesesuaian dengan kondisi daerah tempatan. Dengan adanya penelitian ini diharapkan masyarakat nelayan yang ada disekitar Kabupaten Bengkalis maupun tempat lain yang mengalami permasalahan yang sama dapat melakukan produksi kapal fiberglass secara mandiri untuk mempertahankan profesi dan untuk meningkatkan produktifitas tangkapan mereka. 


\section{METODE}

Fabrikasi kapal fiberglass memerlukan pemahaman dan keterlitian dalam pelaksanaannya. Untuk mendapatkan hasil produk kapal fiberglass yang baik maka perlu dilakukan kajian berbagai referensi dengan cara membaca dan memahami hasil-hasil penelitian maupun buku yang berkaitan dengan fabrikasi kapal fiberglass. Selain itu perlu dilakukan juga update informasi tentang teknologi yang berkembang saat ini berkaitan dengan tema fabrikasi kapal fiberglass.

\subsection{Observasi dan Pengumpulan data}

Pengumpulan data dalam penelitian ini dilakukan dengan cara peninjauan langsung ke lapangan lapangan untuk mendapatkan beberapa data yang diperlukan seperti : ketersediaan material, teknik laminasi yang efektif, cara pencampuran material yang baik dan lain sebagainya. Selain itu perlu dilakukan juga pengumpulan data yang berkaitan dengan ketersediaan tenaga terampil yang akan dipergunakan dalam melakukan fabrikasi kapal tersebut.

\subsection{Metode pembuatan cetakan kapal}

Cetakan (moulded) merupakan komponen yang sangat menentukan dalam proses produksi kapal fiberglass. Dalam fabrikasi kapal fiberglass terdapat 2 metode yaitu dengan cetakan negatif dan cetakan positif. Cetakan negatif menghasilkan bagian dalam yang halus sedangkan cetakan positif menghasilkan permukaan halus bagian luar. Bentuk cetakan mengacu pada gambar rencana garis yang dibuat dengan skala 1:1. Dalam pembuatan cetakan sangat diperlukan ketelitian agar body kapal yang terbentuk nantinya sama dengan gambar yang sudah direncanakan.

\subsection{Laminasi}

Teknologi laminasi adalah teknik penggabungan bahan dengan bantuan perekat, bahan bangunan berukuran kecil dapat direkatkan membentuk komponen bahan sesuai keperluan. Teknik laminasi juga dapat dilakukan untuk menggabungan bahan baku yang tidak seragam atau dari berbagai kualitas(Aditya Amor Patria dan Triwilaswandio Wuruk Pribadi, 2017). Laminasi dilakukan dengan teknik laminasi basah sesuai prosedur standar. Dalam laminasi ini digunakan serat searah untuk mendapatkan kekuatan tarik yang baik sesuai hasil penelitian munasir (munasir, 2011). Dalam penelitian ini dilaminasi menggunakan bahan-bahan pembuat fiberglass (Resin, Woven Roving, Matt, katalis dan pigmen).

\subsection{Peralatan dan material}

Dalam penelitian ini menggunakan peralatan yang diperlukan untuk pembuatan cetakan, mixer pencampur resin pigmen dan katalis, serta berbagai peralatan untuk proses laminasi. Sedangkan bahan yang digunakan diantaranya adalah kayu, resin, moven roving, serat glass dan lain sebagainya. Peralatan dan bahan tersebut sangat menentukan terlaksananya kegaiatn penelitian ini.

\section{HASIL DAN PEMBAHASAN}

Survey lapangan yang telah dilakukan untuk mendapatkan berbagai masukan tentang tata letak kapal, ukuran utama dan berbagai masalah yang dihadapi nelayan pada saat mengoperasikan kapal mereka. Dalam penelitian ini survey dilakukan di 2 lokasi kelompok nelayan yaitu kelompok nelayan yang ada di desa Teluk Papal kecamatan Bantan Kabupaten Bengkalis dan desa Pambang Kecamatan Bantan Kabupaten Bengkalis.

\subsection{Ukuran Utama Kapal}

Data ukuran utama kapal yang dibuat adalah sebagai berikut :

$\begin{array}{ll}\text { Lpp } & : 7.798 \mathrm{~m} \\ \mathrm{~B} & : 1.575 \mathrm{~m} \\ \mathrm{H} & : 0.678 \mathrm{~m} \\ \mathrm{~T} & : 0.4 \mathrm{~m} \\ \mathrm{Cb} & : 0.449\end{array}$

\subsection{Bentuk lambung kapal (Body Plan)}

Bentuk lambung kapal yang dibuat tampak seperti pada gambar dibawah ini.

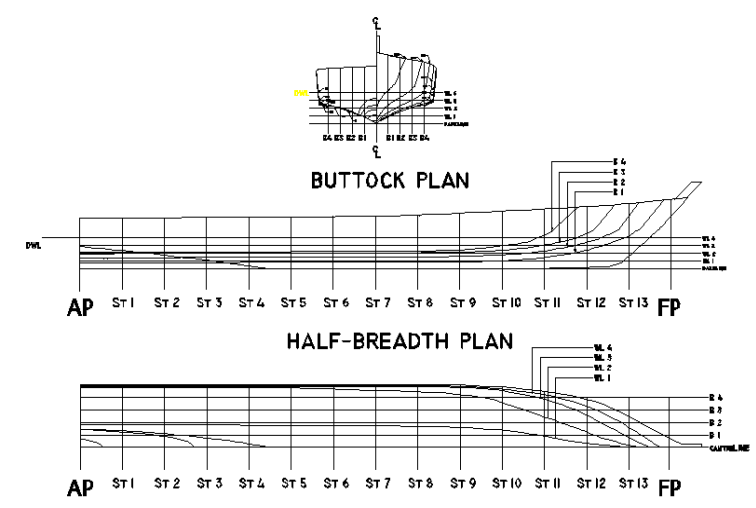

Gambar 1. Lines Plan 


\subsection{General arrangement}

Gambar Rencana Umum yang dibuat dalam penelitian ini.

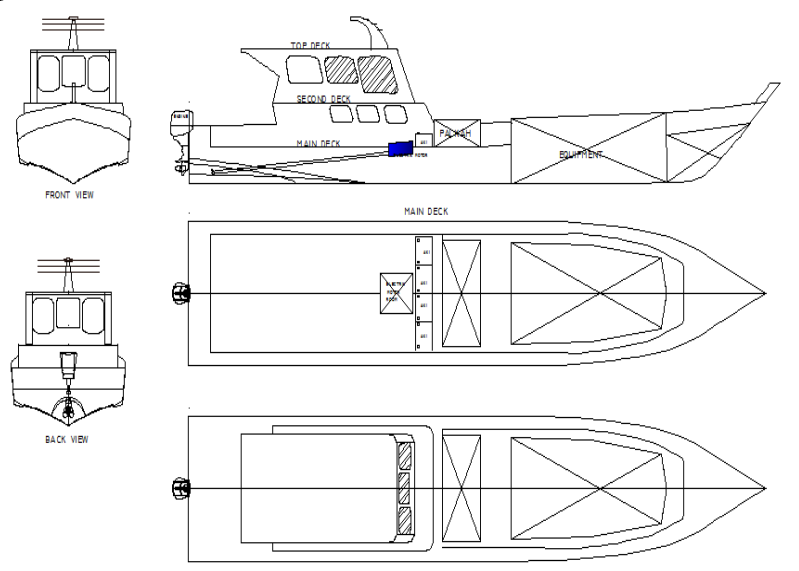

Gambar 2. General Arrangement

\subsection{Pembuatan cetakan positif}

Material yang digunakan dalam membuat bentuk lengkungan setiap station cetakan ini adalah multiplek dengan ketebalan $12 \mathrm{~mm}$. Adapun tahapan prosesnya adalah sebagai berikut :

a. Pengambaran skala 1:1 pada material multiplek $12 \mathrm{~mm}$ untuk setiap bentuk kelengkungan setiap station.

b. Memotong sesuai dengan bentuk kelengkungan yang sudah dibuat pada multiplek $12 \mathrm{~mm}$.

c. Pembuatan pondasi sesuai dengan ukuran dengan mempertimbangkan kekuatan pada saat laminasi.

d. Memasang potongan bentuk body kapal pada pondasi sesuai dengan urutan dari haluan sampai buritan kapal.

e. Memberi penguat cetakan menggunakan kayu 1 x 2 inchi dengan memperhatikan bentuk kelengkungan body kapal.

f. Memasang multiplek $3 \mathrm{~mm}$ sesuai dengan bentuk serta mengikat dengan paku agar tidak bergerak.

g. Melapisi dengan multiplek halus, dengan cara menggunakan lem agar paku tidak terlihat pada bagian terluar cetakan. Pada bagaian terluar cetakan harus dalam kondisi halus.

Berikut ini gambar dari proses pembuatan cetakan tersebut :
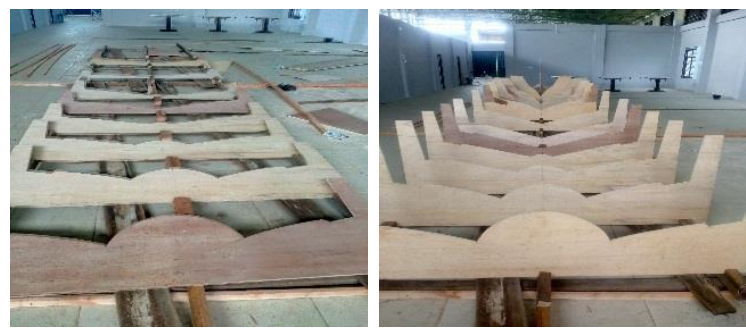
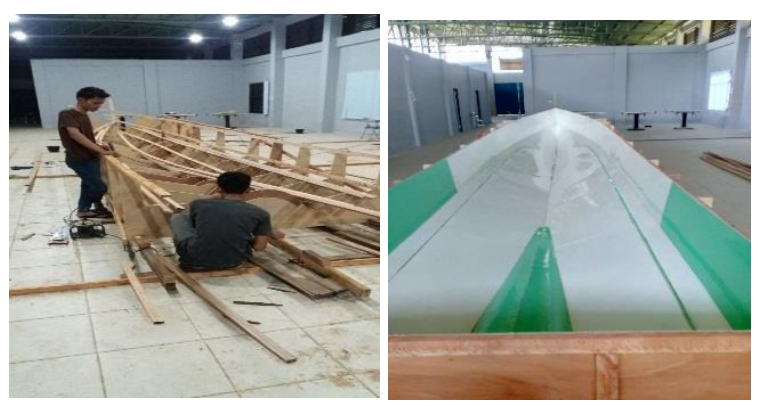

Gambar 3. Pembuatan cetakan

\subsection{Laminasi lambung}

Proses laminasi merupakan tahapan yang cukup penting dalam fabrikasi kapal fiberglass. Kualitas lambung kapal fiberglass sangat tergantung pada proses laminasi ini. Pada penelitian ini laminasi menggunakan cara manual yaitu menggunakan kuas rol. Sebelum proses laminasi cetakan positif lambung kapal diberikan lapisan mirorglass untuk mempermudah proses pelepasan body kapal dari cetakan pada saat selesai laminasi. Setelah itu lapisan berikutnya adalah gealcoat yang dicampur dengan pewarna (pigment) sesuai dengan keinginan. Pemberikan gealcoat ini akan membuat permukaan terluar body kapal menjadi halus sehingga tahanan kapal menjadi kecil.



Gambar 4. Proses laminasi lambung

\subsection{Laminasi frame dan sekat}

Setelah laminasi lambung selesai dan sebelum diangkat dari cetakan maka perlu diberi penguat berupa frame memanjang dan melintang. 
Pembuatan frame memanjang dan melintang dilakukan dengan dua cara yaitu cara pertama menggunakan material kayu yang dibentuk sesuai dengan bentuk frame kemudian dilaminasi ke lambung kapal sehingga menjadi satu kesatuan dengan lambung kapal. Cara kedua menggunakan frame yang terbuat dari material fiberglass, yaitu dengam membuat bentuk frame dengan laminasi fiberglass pada sebuah cetakan kayu kemudian setelah kering hasil laminasi tersebut digunakan untuk frame seperti halnya yang terbuat dari kayu.

\subsection{Bangunan atas}

Pembuatan bangunan atas kapal ini menggunakan material multiplek $12 \mathrm{~mm}$ dan kayu sebagai penguat. Bentuk dan ukuran bangunan atas disesuaikan dengan desain general arrangement. Setelah bentuk bangunan atas selesai maka untuk membuat bangunan lebih awet dan tidak mudah rusak maka dilaminasi menggunakan fiberglass dengan ketebalan 2-3 mm. Berikut ini adalah bentuk bangunan atas kapal ini.

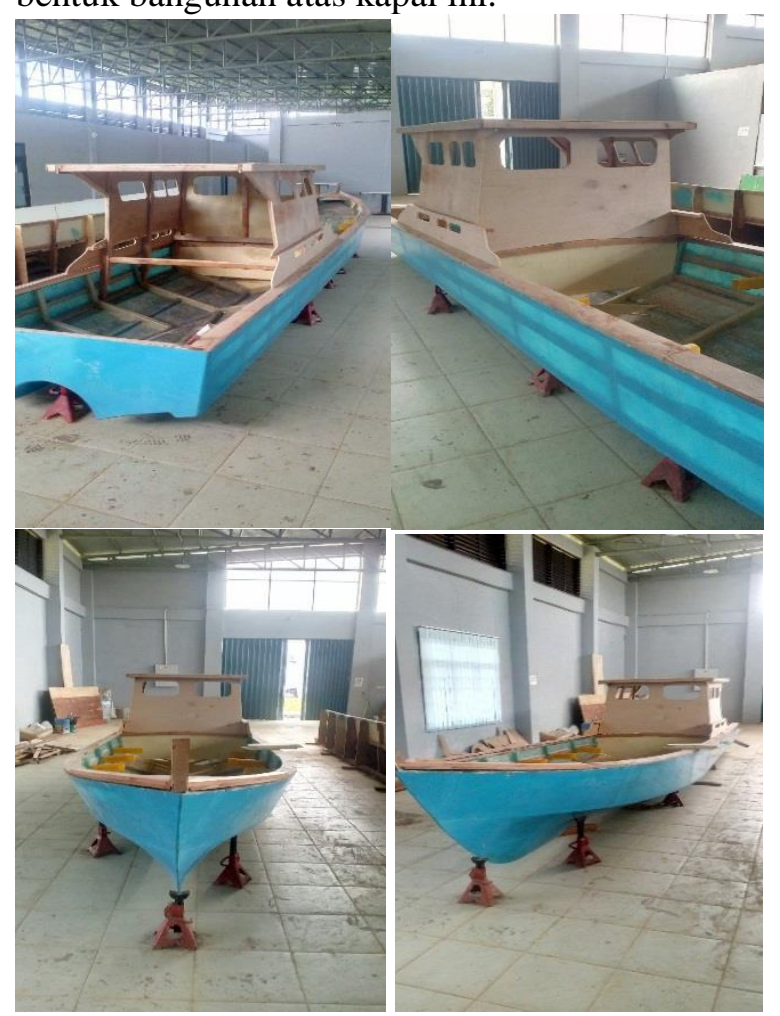

Gambar 5. Bangunan atas kapal

\section{KESIMPULAN}

Berdasarkan hasil pembahasan pada penelitian ini dapat diambil beberapa kesimpulan sebagai berikut :

a. Pembuatan lengkungan cetakan akan lebih efektif dalam membentuk body kapal setiap station dengan menggunakan multiplek $12 \mathrm{~mm}$ atau lebih. b. Dalam proses laminasi perlu memperhatikan banyaknya jumlah campuran katalis dalam resin untuk mendapatkan hasil fiberglass yang mempunyai kualitas baik.

c. Lapisan mirrorglass dan lapisan gealcoat yang rata akan menghasilkan permukaan luar badan kapal yang baik dan mudah dalam pelepasan dari cetakan.

d. Untuk menghambat proses rusaknya kayu yang digunakan dalam bangunan atas kapal dapat menggunakan lapisan fiberglass dengan ketebalan sesuai kebutuhan.

\section{DAFTAR PUSTAKA}

[1] Aditya Amor Patria dan Triwilaswandio Wuruk Pribadi, " Analisis Teknis dan Ekonomis Pembangunan Kapal Ikan Tradisional Ukuran <10 GT Berbahan Kayu Utuh Dengan Teknologi Laminasi Kayu Mahoni", JURNAL TEKNIK ITS Vol. 6, No. 1, (2017)

[2] D Ardiana, R Razali, M Muharnis, 2014. " Proses Pembuatan Kapal FRP Berkapasitas 14 M Bagi Nelayan di Kabupaten Bengkalis ". INOVTEK POLBENG, 2014

[3] Anwar Khaerul, 2012. " Analisis Produksi Kapal Perikanan Berbahan Dasar Kayu dan Fiberglass " IPB. Bogor

[4] Buana Ma'ruf, 2011. " Studi Standarisasi Konstruksi Laminasi Lambung Kapal Fiberglass" . Jurnal Standarisasi. Vol.13 No.1 halaman 16-25.

[5] Munasir, " Studi Pengaruh Orientasi Serat Fiber Glass Searah dan Dua Arah Single Layer terhadap Kekuatan Tarik Bahan Komposit Polypropylene ", Jurnal Penelitian Fisika dan Aplikasinya (JPFA), Vol. 1 No. 1, Juni 2011

[6] SA Muharam. 2011. " Desain dan Konstruksi Kapal Pibreglass di PT. Carita Boat Indonesia Kecamatan Setu, Kota Tangerang Selatan, Banten ".IPB. Bogor

[7] Parlindungan Manik dan Eko Sasmito Hadi, 2008. " Analisa Teknis dan Ekonomis Penggunaan Coremat Untuk Konstruksi FRP (fiberglass reinforced plastic) Sandwich Pada Badan Kapal " Jurnal KAPAL, Vol. 5, No.2, Juni 2008

[8] Korol, I and Latorre, R., 2010. "Development of Eco-Friendly Fishing Vessel An Ecological Vehicle Powered by Renewable Energy". 
Ecological Vehicles. Renewable Energies.

Monaco, March 25 - 28, 2010.

[9] Jurusan Teknik Perkapalan, FTK - ITS. Diktat rencana garis.

[10] Jurusan Teknik Perkapalam, FTK - ITS. Diktat rencana umum. 